\title{
Expert forum releases roadmap for drug reform
}

\author{
Cite as: CMAJ 2017 August 14;189:E1048-9. doi: 10.1503/cmaj.1095464
}

Posted on cmajnews.com on July 25, 2017.

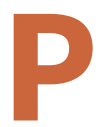

revention, harm reduction and treatment of addiction should be cornerstones of Canada's drug policies going into the future - not criminalization, according to an expert forum.

In April, Canada's Drug Futures Forum brought together researchers, policymakers, public health officials, law enforcement professionals, community organizers and people who use drugs to set a 10-year agenda for reform. In a new report, they urge a "new direction for Canadian drug policy" that promotes public health over prohibition.

Penalizing people who use drugs has been a "masterful distraction" from "deeper discussion of what's causing severe problematic substance use," said Donald MacPherson, executive director of the Canadian Drug Policy Coalition, in a recent webinar. "We have to move away from the hundred years of prohibition toward an above-ground regulatory approach."

The need for reform has never been more urgent, MacPherson said. "We have an inability to respond rapidly to things like the overdose crisis," in large part because "we don't have the capacity to move outside the box of the criminalized context that we've inherited from the past."

The report proposes using the window of opportunity created by marijuana legalization to re-examine regulation of other substances, including alcohol, tobacco and pharmaceuticals. "We cannot make decisions about changing the scope of regulation or control of one drug without revisiting the ways other drugs are controlled, to ensure we don't incentivize one drug over the other," explained Dan Werb, executive director of the International Centre for Science in Drug Policy and chair of the forum organizing committee.

The report recommends that governments conduct tests to predict the

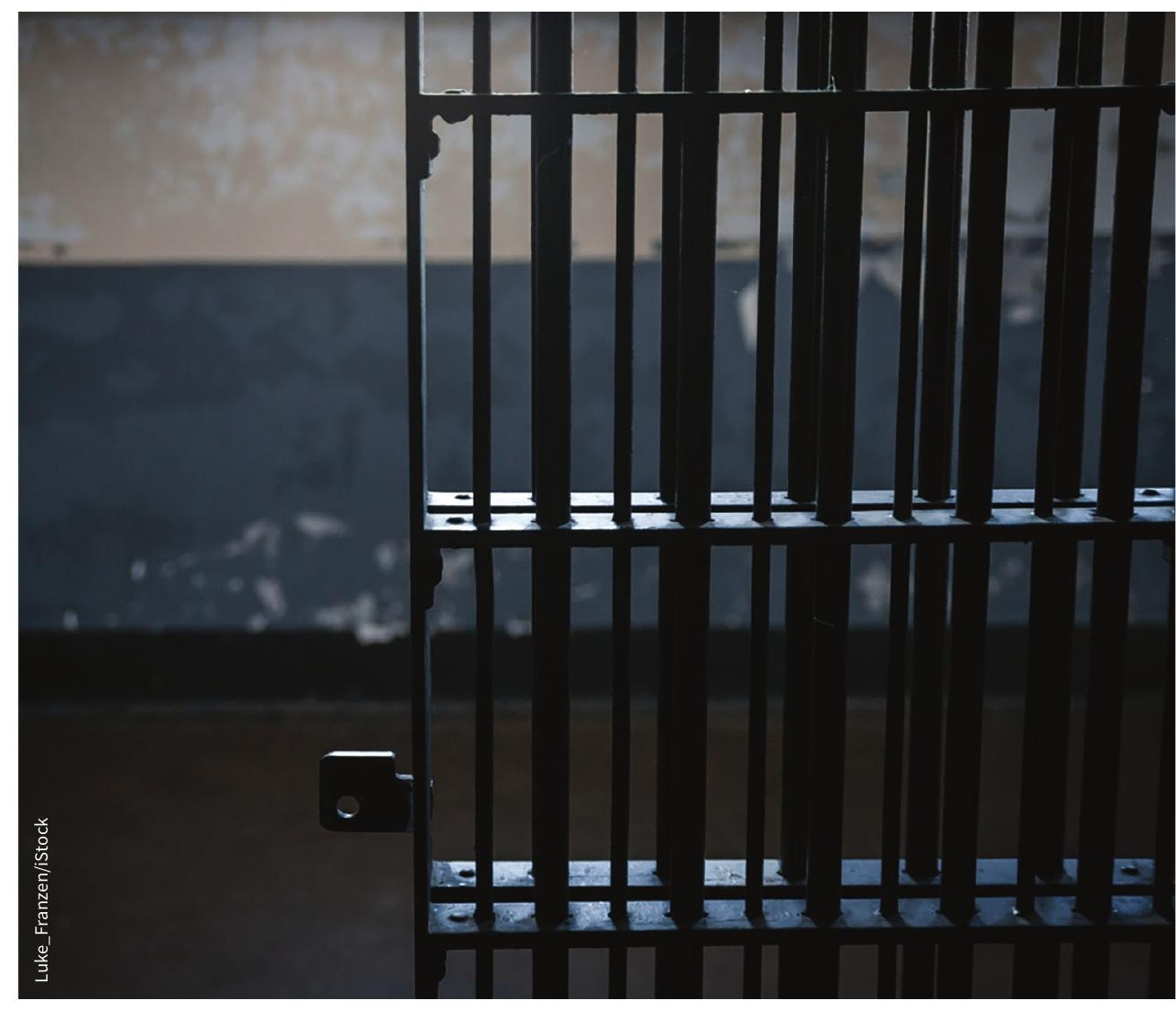

Criminalization shouldn't be the foundation of drug policy, says expert forum.

impact of drug policies, including potential unintended or unforeseen consequences, especially decisions to restrict access to a drug, such as opioids. "There has to be some consideration and scale up of services" to ensure people aren't cut off without alternative treatments, said Werb.

The report also calls on governments to commit a portion of tax revenues from legal pot sales to "directly address the needs of communities most deeply impacted by drug criminalization." In the long-term, it proposes the creation of a federal commission that would review the costs and benefits of current drug control policies and explore steps towards decriminalization for each class of illegal drugs, as well as redress for those harmed by prohibitive policies.

Since "the harms of incarceration, in particular, often outweigh its supposed benefits," the report further recommends that criminal justice should play a decreasing role in drug policy, Two shortterm solutions include expanding access to drug treatment courts and other diversion programs without requiring individuals to plead guilty, and instructing prosecutors to stop pursuing charges for personal possession and use of cannabis until new laws are implemented. 
People discharged from Canada's criminal and welfare systems face a higher risk of overdose, and their discharge plans should include harm reduction strategies, treatment and monitoring, the report states.

More generally, governments should commit to providing and monitoring harm reduction and treatment programs, including supervised consumption sites and naloxone kits, and implement "drug checking services" as a consumer safety measure.

Such reforms are "long overdue" and timely, given ongoing provincial consultations on marijuana regulation, said Dr. Mark Ware, a pain specialist and vicechair of the federal Task Force on Cannabis Legalization and Regulation.

Global consensus over drug control is fraying and Canada has the potential to champion a public health approach, even as the United States pushes for a renewed war on drugs. "Canada's role is less likely to be one of chest-beating bravado about drug reform but quiet consensus building in countries that are seriously considering this approach," Ware said.

Lauren Vogel, CMAJ 